\title{
BIOLOGÍA MOLECULAR EN EL DIAGNÓSTICO DE NEOPLASIAS INTRAEPITELIALES DE CÉRVIX UTERINO
}

\section{Molecular Biology In The Diagnosis Of Intraepitheliales Neoplasms Of Uterine Cervix \\ EDITORIAL}

\author{
Nazario A. Ortiz-Muchotrigo ${ }^{1, a}$, Jorge Ybaseta-Medina ${ }^{2, b}$. \\ 1. Universidad Peruana Cayetano Heredia. Lima, Perú. \\ 2. Universidad Nacional San Luis Gonzaga de Ica. Ica, Perú. \\ a. Médico especialista en Patología y Laboratorio Clínico, subespecialidad en \\ Patología Oncológica del Hospital Santa Rosa de Lima, Lima, Perú. \\ b. Gineco-Obstetra del Hospital Santa María del Socorro de Ica, Perú.
}

En los últimos años, las técnicas inmunohistoquímicas han contribuido a mejorar el diagnóstico y pronóstico en los diferentes casos de neoplasias malignas, entre tales técnicas se destacan el anticuerpo monoclonal $\mathrm{Ki}-67$ que es un marcador de proliferación celular activa para facilitar la detección de células anormales en muestras de citología o tejido, y P16 (INK4a) es un marcador supresor del tumor, es uno de los encargados de regular el ciclo celular (1). Estos biomarcadores proteicos actualmente disponibles para su uso en el cribado del cáncer de cuello uterino, que parecen ofrecer mejoras en la detección de mujeres con mayor riesgo de desarrollar cáncer de cuello uterino (2).

El cáncer de cuello uterino es un problema de salud pública, y la primera causa de muerte por cáncer en las mujeres del Perú. El despistaje del cáncer de cuello uterino se realiza a través del Papanicolaou (PAP) (3), sin embargo la eficacia de este tamizaje tiene una baja sensibilidad cercana al $50 \%$ en el mejor de los casos (4), tasa elevada de resultados falsos negativos, resultados no disponibles de inmediato, la mujer debe realizarse el tamizaje con mayor frecuencia y requiere de una infraestructura compleja (5). Se estima que cuando se aplican métodos de diagnóstico precoz se podrían prevenir almenos el $40 \%$ de casos de cáncer de cuello uterino.

El mayor porcentaje de cáncer de cérvix son producidos por el papiloma virus humano de alto riesgo (P.V.H-AR) y que los genotipos 16 y 18 son los responsables de aproximadamente el $70 \%$ de ellos. La detección de la infección por P.V.H, generalmente se realiza con el tamizaje de Papanicolaou que dirige el ministerio de Salud, ese tamizaje se realiza por las características citológicas de la célula, actualmente existe diferentes pruebas moleculares y test que se encuentra concentrado en la capital que tiene un costo elevado; sin embargo existe pruebas moleculares de costo accesible, rápido y confiable, es la técnica de inmunohistoquimica p16 y Ki-67, la tinción dual que utiliza anticuerpos monoclonales, que se realiza en las extensiones citológicas, son uno de los test más importantes para identificar lesiones cervicales premalignas considerándose como test positivo la presencia de una o más células que coexpresen ambos anticuerpos en el mismo tiempo. La sensibilidad y especificidad de estos biomacadores es cerca del $90 \%$ y $80 \%$ cuando las muestras son adecuadamente procesadas y almacenadas, Esta técnica debe ser considerada por el MINSA para el programa de detección de cáncer, por las siguientes ventajas:

- $\quad$ El anticuerpo monoclonal p16 (INK4a) además de su expresión positividad o negatividad puede proporcionar información diagnostica y pronostica para el tratamiento de pacientes con lesiones de bajo grado.

- $\quad$ Los beneficios de usar esta tinción dual facilita el diagnóstico diferencial entre los simuladores de lesión cervical (metaplasma escamosa inmadura, cambios celulares asociados a atrofia e inflamación) y las verdaderas lesiones intraepiteliales de alto grado.
BIBLIOGRAFIA

1. Barrios García L, Agressott Beltran LM. Expresión simultaneal de los marcadores p16INK4a y ki67 en extendidos de citología cérvico-vaginal anormales de archivo, Medina y Laboratorio 2014; 20: 73-86.

2. Brow CA, Boyers J, Sahebali S, Depuydt CE, De Prins $F$, Malinowski DP. Role of protein biomarkers in the detection of high-grade disease in cervical cancer screening programs. J Oncol 2012; 2012: 289315

https://www.ncbi.nlm.nih.gov/pub $\mathrm{med} / 22481919$

3. Documento Técnico: Plan Nacional de Prevención y Control de Cáncer de Cello Uterino 2017 2021

4. ACCP. Pap smears: An important but imperfect method. Cervical Cancer Prevention Fact Sheet. (October 2002).

5. Agency for Health Care Policy and Research (AHCPR). Evaluation of Cervical Cytology. Evidence Report/Technology Assessment, No. 5. Rockville, MD. (1999).

\section{CITAR COMO:}

Muchotrigo - Ortiz Nazario, Ybaseta - Medina Jorge. Biología molecular en el diagnóstico de neoplasias intraepiteliales de cérvix uterino. Rev. méd. Panacea. 2017; 6 (3): $88-89$ 
- La expresión simultánea de p16 y Ki67 en una misma célula es signo inequívoco de haber sido transformada por la infección por papiloma virus humano alto riesgo (P.V.H $A R$ ), reduciendo significativamente la variabilidad interobservador en la lectura citológica. Aclarando el diagnóstico y otorgar el tratamiento adecuado (1).

- $\quad$ La expresión simultánea de p16 y Ki67 en una misma célula presenta una alta sensibilidad y especificidad para el diagnóstico histológico de CIN 2+. Con este resultado la paciente debe ser sometidas a tratamiento quirúrgico (1).

- $\quad$ Otras de las ventajas es la expresión simultánea de p16 y Ki67 en una misma célula muestra utilidad y eficacia en el scrining citológico de ASCUS y LSIL en pacientes con papiloma virus humano de alto riesgo positivas.

Se recomienda a las autoridades de MINSA, inicialmente difundir la técnica de inmunohistoquimica y empezar por entrenar al personal que labora en el departamento y/o Servicio de Anatomía Patológica de los hospitales Regionales del interior del País. Esta doble tinción también podría ser utilizada para aumentar la sensibilidad en programas de despistaje de cáncer de cérvix, especialmente en lugares con menos recursos económicos por ser un test relativamente económico, rápido y accesible a la población. 